\section{(2) OPEN ACCESS}

- Additional material is published online only. To view please visit the journal online (http://dx.doi.org/10.1136/ gutjnl-2020-321244)

For numbered affiliations see end of article.

\section{Correspondence to} Professor Charlie W Lees, Institute of Genetics \&

Molecular Medicine, University of Edinburgh, Edinburgh, EH4 2XU, UK; charlie.lees@ed.ac.uk

NAK, G-RJ and CAL are joint first authors.

Received 28 March 2020 Revised 3 April 2020 Accepted 6 April 2020 Published Online First 17 April 2020

\title{
British Society of Gastroenterology guidance for management of inflammatory bowel disease during the COVID-19 pandemic
}

\author{
Nicholas A Kennedy (D) ,'2 Gareth-Rhys Jones (D) ,', Christopher A Lamb (D) ,,6 \\ Richard Appleby (D) , ${ }^{7}$ Ian Arnott (D) , ${ }^{4}$ R Mark Beattie (D) , ${ }^{8}$ Stuart Bloom (D) , \\ Alenka J Brooks (D) , ${ }^{10}$ Rachel Cooney (D) , 11,12 Robin J Dart (D) , 13,14 \\ Cathryn Edwards (D) , ${ }^{15}$ Aileen Fraser (D) , ${ }^{16}$ Daniel R Gaya (D) , 17,18 \\ Subrata Ghosh (D) , ${ }^{11,12}$ Kay Greveson (D) , ${ }^{14}$ Richard Hansen (D) , ${ }^{18,19}$ \\ Ailsa Hart (D) , ${ }^{20,21}$ A Barney Hawthorne (D) , 22 Bu'Hussain Hayee (D) , 13,23 \\ Jimmy K Limdi (D) ${ }^{24,25}$ Charles D Murray (D) , ${ }^{14}$ Gareth C Parkes (D) , ${ }^{26,27}$ \\ Miles Parkes (D) ${ }^{28}$ Kamal Patel, ${ }^{29}$ Richard C Pollok (D) , ${ }^{29,30}$ Nick Powell (D) , ${ }^{21,31}$ \\ Chris S Probert (D) , ${ }^{32,33}$ Tim Raine (D) ,' 28 Shaji Sebastian (D) , \\ Christian Selinger (D) , ${ }^{35}$ Philip J Smith (D) , ${ }^{32}$ Catherine Stansfield (D) , 36 \\ Lisa Younge (D) ${ }^{37}$ James 0 Lindsay (D) , ${ }^{26,27}$ Peter M Irving (D) , 13,38 \\ Charlie W Lees (D) ${ }^{3,4}$
}

\section{ABSTRACT}

The COVID-19 pandemic is putting unprecedented pressures on healthcare systems globally. Early insights have been made possible by rapid sharing of data from China and Italy. In the UK, we have rapidly mobilised inflammatory bowel disease (IBD) centres in order that preparations can be made to protect our patients and the clinical services they rely on. This is a novel coronavirus; much is unknown as to how it will affect people with IBD. We also lack information about the impact of different immunosuppressive medications. To address this uncertainty, the British Society of Gastroenterology (BSG) COVID-19 IBD Working Group has used the best available data and expert opinion to generate a risk grid that groups patients into highest, moderate and lowest risk categories. This grid allows patients to be instructed to follow the UK government's advice for shielding, stringent and standard advice regarding social distancing, respectively. Further considerations are given to service provision, medical and surgical therapy, endoscopy, imaging and clinical trials.

\section{INTRODUCTION}

Inflammatory bowel disease (IBD), comprising Crohn's disease (CD) and ulcerative colitis (UC), is a condition in which the gastrointestinal immune system responds inappropriately. IBD is therefore often treated with immunosuppressing medications to control inflammation and prevent 'flares', a worsening of symptoms, which may be unpredictable.

While it is known that $0.8 \%$ of people in the UK currently have IBD (approximately 524000 patients), only $44 \%$ have been to a clinic in the past 3 years $^{12}$. There will be many patients who are worried about the effect of the coronavirus pandemic (SARS-CoV-2 or COVID-19 disease) on their IBD and vice versa, many of whom will be unknown to secondary care.

During the COVID-19 outbreak, we will do everything we can to keep our IBD patients safe. The greatest risks relate not only to the infection itself, but also the emergency reorganisation of hospital and general practice services to deal with the pandemic. This will result in significant changes to routine IBD services. A combined approach covering both primary and secondary care is therefore required to keep vulnerable patients with IBD out of hospital as much as possible.

Insights from Hubei, China and from Italy suggest hospital attendance for non-COVID-19 illness may provide a reservoir for further spread of infection. However, alterations to the way we deliver IBD care in the UK must be balanced against the risks of under treated, active IBD. Importantly, patients with active IBD are likely to have a higher risk of infection both in the community and during inpatient care, even in the absence of immunosuppressive treatment. ${ }^{3}$ Therefore, it is of paramount importance to control intestinal inflammation in IBD to prevent adverse outcomes.

\section{COVID-19 DISEASE AND IBD}

The impact of immunosuppression on the severity of COVID-19 disease remains unclear. Data reported from 1099 Chinese patients with COVID-19 did not observe immunodeficiency as a risk factor for severe disease (defined according to the American Thoracic Society guidelines for community acquired pneumonia). ${ }^{4}$ The currently understood predictors associated with COVID-19 mortality at the time of hospital admission are older age (OR $1.1 ; 95 \%$ CI 1.03 to 1.17 per year increase), higher 
sequential organ failure assessment score (OR 5.65; 95\% CI 2.61 to 12.23 ) and d-dimer $>1 \mu \mathrm{g} / \mathrm{mL}$ (OR 18.42; $95 \% \mathrm{CI} 2.64$ to 128.55). ${ }^{5}$ However, smoking, comorbidity, particularly hypertension, vascular disease, diabetes and male sex have been associated with poor outcome. ${ }^{4-9}$ Prolonged illness and complications from respiratory infection are perhaps more common when non-steroidal anti-inflammatory drugs (NSAIDs) are used, but no data in COVID-19 currently exist. ${ }^{10}{ }^{11}$ Given NSAIDs have also been implicated in IBD flare, paracetamol is advocated as firstline analgesia/antipyretic. ${ }^{12}$

At the time of writing, the Surveillance Epidemiology of Coronavirus Under Research Exclusion (SECURE)-IBD registry has reported 239 (54\% male) cases of COVID-19 in IBD patients (137 CD, 94 UC, 5 IBD unclassified), of whom 64 were hospitalised and 11 patients died. ${ }^{13}$ Seven patients underwent ventilation. Among the 11 patients who died, a range of medications were seen; five patients were receiving mesalazine alone or no therapy, although all were aged 69 years or older; four were receiving steroids alone or in combination; and the youngest patient who died was 33 years and was receiving combination therapy with adalimumab, azathioprine and prednisolone. ${ }^{13}$ The British Society of Gastroenterology (BSG), in line with the International Organisation for the Study of IBD and the European Crohn's and Colitis Organisation, recommend that patients with IBD do not routinely stop their medication to prevent infection or adverse outcome with COVID-19. ${ }^{14} 15$

'Social distancing' (https://www.gov.uk/government/ publications/covid-19-guidance-on-social-distancing-andfor-vulnerable-people/guidance-on-social-distancing-foreveryone-in-the-uk-and-protecting-older-people-and-vulnerable-adults) and 'shielding' (https://www.gov.uk/government/ publications/guidance-on-shielding-and-protecting-extremelyvulnerable-persons-from-covid-19/guidance-on-shielding-andprotecting-extremely-vulnerable-persons-from-covid-19) are measures to reduce spread within the population and to protect high risk groups. These are also an understandable source of anxiety for patients with IBD. ${ }^{16}$

On behalf of the BSG, a UK-wide IBD COVID-19 Working Group has been established and has defined patient risk as highest, moderate and lowest for COVID-19 related poor outcome (see table 1 and below for justification of groupings). Patients classified as at highest risk, correspond to group 5 in the UK government's instruction to undergo 'shielding', the most stringent form of isolation. The moderate group are recommended to be even stricter at following the government's instructions regarding social distancing. Note that all patients should still attend for infusions of biologics, irrespective of risk stratification.

The UK Department of Health has requested patient contact details from local secondary care IBD services for those that meet the highest risk. A pragmatic approach to identify individuals within the highest risk group has been adopted:

1. Where feasible, national datasets are being interrogated to identify 'highest risk' patients.

2. Direct communication with patients via the BSG, and Crohn's and Colitis UK workflows.

3. Patients may self-identify into risk group (https://www.ibdregistry.org.uk/covid-19) and/or contact their local IBD team (ideally by email).

4. Secondary care IBD teams will then provide patient details to the National Health Service (NHS).

The self-identification tool (point 3 above) was developed using the information in table 1 in partnership with the IBD Registry as a pragmatic solution to obtain up to date information from UK patients with IBD and maximise the ability to identify patients in the highest risk group. Early identification and intervention (shielding education) to 318 Chinese IBD patients in Hubei at risk of COVID-19 was well received by patients and

Table 1 British Society of Gastroenterology inflammatory bowel disease COVID-19 risk grid: Stratification of risk of serious COVID-19 disease into highest, moderate and lowest risk categories for patients with inflammatory bowel disease

\begin{tabular}{|c|c|c|}
\hline $\begin{array}{l}\text { Highest risk } \\
\text { 'shielding' }\end{array}$ & $\begin{array}{l}\text { Moderate risk } \\
\text { 'stringent social distancing'* }\end{array}$ & $\begin{array}{l}\text { Lowest risk } \\
\text { 'social distancing' }\end{array}$ \\
\hline $\begin{array}{l}\text { 1. IBD patients who either have a comorbidity (respiratory, } \\
\text { cardiac, hypertension or diabetes mellitus) and/or are } \geq 70 \\
\text { years old andt are on any 'moderate risk' therapy for IBD } \\
\text { (per middle column) and/or have moderate to severely active } \\
\text { disease } \\
\text { 2. IBD patients of any age regardless of comorbidity and who } \\
\text { meet one or more of the following criteria: } \\
\text { - Intravenous or oral steroids } \geq 20 \text { mg prednisolone or } \\
\text { equivalent per day (only while on this dose) } \\
\text { - Commencement of biologic plus immunomodulator or } \\
\text { - systemic steroids within previous } 6 \text { weeks } \ddagger \\
\text { - Moderate to severely active disease } \$ \text { not controlled by } \\
\text { - Shoderate risk' treatments } \\
\text { - Requirement for parenteral nutrition }\end{array}$ & $\begin{array}{l}\text { 1. Patients on the following medications } 9 \text { : } \\
\text { - } \text { Anti-TNF (infliximab, adalimumab, golimumab, } \\
\text { - certolizumab) monotherapy } \\
\text { - Biologic plus immunomodulatorł in stable patients } \\
\text { - Ustekinumab } \\
\text { - Vedolizumab } \\
\text { - Thiopurines (azathioprine, mercaptopurine, tioguanine) } \\
\text { - Methotrexate } \\
\text { - Calcineurin inhibitors (tacrolimus or ciclosporin) } \\
\text { - Janus kinase (JAK) inhibitors (tofacitinib) } \\
\text { - Immunosuppressive trial medication } \\
\text { - Mycophenolate mofetil } \\
\text { - Thalidomide } \\
\text { - Prednisolone }<20 \text { mg or equivalent per day } \\
\text { 2. Patients with moderate to severely active disease } \S \text { who are } \\
\text { not on any of the medications in this column }\end{array}$ & $\begin{array}{l}\text { Patients on the following medications: } \\
\text { 5-ASA } \\
\text { Rectal therapies } \\
\text { Orally administered topically acting steroids } \\
\text { (budesonide or beclometasone) } \\
\text { Therapies for bile acid diarrhoea (colestyramine, } \\
\text { colesevelam, colestipol) } \\
\text { Antidiarrhoeals (eg, loperamide) } \\
\text { Antibiotics for bacterial overgrowth or perianal } \\
\text { disease }\end{array}$ \\
\hline
\end{tabular}

No specific recommendations are being made regarding IBD and pregnancy, and pregnant women with IBD are encouraged to follow the guidance available from the UK government for pregnant women in the general population.

This guidance was last updated by the BSG COVID-19 IBD Working Group on 2 April 2020, and was based on expert opinion and the available evidence at the time.

*The UK government advises those at increased risk, but not reaching the highest risk, of severe illness from coronavirus (COVID-19) to be particularly stringent when applying social distancing recommendations.

†That is, at least one of (comorbidity listed above or age $\geq 70$ years) plus at least one of (therapy from middle column or moderate to severely active disease).

$\ddagger$ Patients should be categorised as highest risk (requiring shielding) within 6 weeks of starting biologics if they are on concomitant immunomodulator treatment or systemic steroids, whether started simultaneously or prior to the biologic. After 6 weeks they may enter the 'moderate' risk category provided they do not meet other highest risk criteria, for example, moderate-severe disease not controlled by treatment. Biologic plus immunomodulator in stable patients may increase the risk over monotherapy but there is no specific evidence for this situation. $\S$ As judged by the clinical team responsible for patient care.

IPatients who have stopped biologics or immunomodulators should remain within their pre-treatment cessation risk category for 3 months; for drugs with a much shorter half-life (eg, tofacitinib), we advise clinician discretion.

5-ASA, 5-aminosalicylic acid; IBD, inflammatory bowel disease; TNF, tumour necrosis factor. 
may have protected them from infection, with none of them reporting infection, as of 28 February $2020 . .^{17}$

At the time of writing, there is a lot of activity at UK government level around the wearing of masks by the general population in public spaces and hospitals. The BSG recommends members of the public to follow the most up to date advice from the government with respect to this.

Most IBD patients will fall into the moderate or lowest risk groups. Defining a 'highest risk' group is not exact, with little or no evidence specific to COVID-19. The grouping has therefore been determined following extensive discussion among UK IBD specialists with input from international colleagues. Based on the current evidence, we understand increasing age, heart disease, diabetes and hypertension are the among the greatest risk factors for poor outcome in COVID-19. ${ }^{4-9}$ As such, priority has been given to these factors alongside medications, other than individuals on high dose steroids (table 1 and below). Where risk is primarily determined by IBD (patient and treatment factors), we recognise this is a dynamic process-that is, patients may move between risk categories over the duration of the pandemic.

This is a very busy time for clinical teams with redeployment in order to manage the COVID-19 pandemic. We have therefore aimed for simple clear messages wherever possible. For this reason, we have deliberately not provided a drug by drug description of clearance, and recommend it is 3 months after cessation of a drug therapy before a patient changes risk category. In part, this is to discourage the practice of stopping drugs purely to switch risk category. The exception is steroids, which is covered explicitly in the grid. As a working group, we have had some discussion about tofacitinib which has a much shorter halflife; in this case, we advise clinician discretion regarding the time point at which cessation impacts on risk categorisation.

We wish to strongly emphasise:

- Patients should continue their current medications.

- Access to injectable treatment (infliximab, vedolizumab, ustekinumab, adalimumab, certolizumab and golimumab) should be maintained, irrespective of risk category and distancing/isolation recommendations.

- Infusion suite services (with appropriate social distancing methods) should be maintained as a priority area to prevent treatment flare, admission and increased risk of immunogenicity.

- Home care provision of subcutaneous medicines should be maintained as a priority for IBD patients.

General advice for all IBD patients is provided in box 1 .

\section{CHANGES TO CURRENT PRIMARY AND SECONDARY CARE PRACTICES}

Hospital services are being reorganised to better deal with severe COVID-19 infections. Elective work is being suspended to maximise staffing and space for acute admissions. We also need to be very careful that rapid institution of telemedicine services does not adversely impact on primary care (eg, phlebotomy and drug prescribing).

Consideration should be given to reorganising services to support well staff working from home when possible, to minimise their own viral exposure. Staff sickness is likely to become a major factor during this pandemic and so efforts should be made to minimise this from the earliest stages.

Pre-symptomatic transmission has been reported, although estimated rates vary between studies. Face to face meetings between staff, particularly in confined spaces, should be minimised and, where necessary, should avoid people being in close
Box 1 Top 10 tips for everyone with inflammatory bowel disease during the COVID-19 pandemic

1. We will do everything we can to keep you safe and well during the COVID-19 pandemic. Note that hospitals are undergoing massive reorganisation to prepare to care for those with serious infection.

2. Don't stop your medication; preventing disease flares is a priority. We want to keep you out of hospital if possible, but if you are unwell, we will be there for you.

3. Ensure you have a good supply of medication should you need to self-isolate or shield yourself. Do not take steroids (prednisolone) from your general practitioner without discussing with your local inflammatory bowel disease (IBD) team.

4. Contact your local IBD team via telephone or email helplines if you are experiencing a flare.

5. Wash your hands frequently and avoid touching your face; this goes for everyone.

6. Work from home if possible, and avoid non-essential travel and contact with people who are currently unwell.

7. Stop smoking, as this increases the risk and severity of COVID-19 infection, and avoid non-steroidal antiinflammatory drugs (eg, ibuprofen).

8. Government guidelines on self-isolation and social distancing are changing rapidly so please visit www.gov.uk and www.nhs.uk to keep up to date. (If you are unclear on your level of risk, contact your local IBD helpline for further advice).

9. If you, or a household member, develop a continuous cough, flu-like symptoms OR fever you should:

a. follow the government's recommendations about selfisolation and household quarantine

b. if you test positive for COVID-19 you should contact your IBD team

C. stop taking medicines in the middle column of table 1. Steroids should be tapered with advice from the IBD team and not stopped abruptly. Fourteen days after your symptoms have resolved, or if a household member is affected, the household quarantine period ends, contact your local IBD team for advice regarding restarting your medication.

d. if you feel you cannot cope with your symptoms at home, or your condition gets worse, or your symptoms do not get better after 7 days, then use the NHS 111 online coronavirus service. If you do not have internet access, call NHS 111. For a medical emergency dial 999.

10. Take care of yourself but also be kind and considerate to others in these difficult times.

proximity if possible. Services such as Microsoft Teams (https:// teams.microsoft.com), WebEx (https://www.webex.com) and Zoom (https://zoom.us) can be used to facilitate virtual meetings (see also https://www.ecdc.europa.eu/sites/default/files/ documents/RRA-sixth-update-Outbreak-of-novel-coronavirusdisease-2019-COVID-19.pdf).

\section{IBD nurse phone and email helpline}

To manage and support patients with IBD when outpatient clinics are being converted to telephone review, the minimum service provision needs to include a telephone/email helpline to support patients having disease flares and to answer queries 
regarding immunosuppressant/biologics management. Ideally, provision should be made for one member of the nursing team to work from home to ensure this is maintained, with appropriate senior review to support the clinical decision making process. This would reduce the burden on both primary and secondary care, in particular the accident and emergency department. This should be supported with capacity for patients to have urgent review if needed in a 'safe clinic'.

Patients are being asked to keep taking their usual IBD therapy. If patients stop taking their medications without discussing it with their clinical team first, there is a risk of disease flare. Active disease is associated with an increased risk of infection, exposure to steroids (increased risk from infection), hospitalisation and major surgery. ${ }^{3} 18$

\section{Outpatient clinics}

Conduct clinical appointments by telephone or a formal telemedicine system where possible. Routine bloods may be deferred until the situation has improved, depending on local capacity. Access to faecal calprotectin (FC) testing, a potential alternative to endoscopy, may become limited due to the presence of virus in the stool. If accessible, consider introduction of point of care calprotectin testing. FC point of care kits could be most effectively issued to high risk patients at a new patient/flare clinic or on discharge from hospital (sampling every 2-3 months depending on capacity). Given the limited access to endoscopic disease assessment, the combination of $\mathrm{FC}$ and clinical disease scores (eg, partial Mayo/Simple Clinical Colitis Activity Index, Paediatric Ulcerative Colitis Activity Index, Harvey-Bradshaw index or weighted Paediatric Crohn's Disease Activity Index) may help to guide treatment decisions more objectively.

\section{New IBD patients}

In line with the Joint Advisory Group/BSG endoscopy guidance released on 26 March 2020, all non-emergency endoscopy should stop immediately. Careful case by case discussion will need to be given to decide the timing of diagnostic endoscopy for the most urgent suspected new IBD cases. If centres are delayed in assessing new IBD patients, a telephone triage system should be adopted to assess clinical urgency.

\section{Urgent outpatient review}

Patients who may require hospitalisation will need to continue to be assessed in a timely manner. Consider the most appropriate location to do this that is away from COVID-19 assessment areas. Daily 'flare clinics' (virtual where possible) with limited numbers of patients who are at high risk of imminent hospitalisation should be considered. Where possible, limit visits to hospital and limit the patient journey around the hospital geographically.

\section{GENERAL CONSIDERATIONS REGARDING IBD MEDICATIONS}

- Balance the risk of immune modifying drugs with the risk associated with active disease.

- Patients are advised not to stop or reduce their medication without discussing with the IBD team, due to the risk of flare leading to a need for steroids or other additional immunosuppression or hospitalisation.

- Immunosuppressive effects of medications may persist for many weeks or months after treatment cessation.

- Identify an experienced/senior person to oversee blood tests, initiation of biologics and prescribing of biologics, and support patients accordingly. Reduce any therapy associated monitoring blood tests to a minimum safe frequency.
- Administrative support should be identified to ensure prescriptions for subcutaneous biologics are forwarded to home care in a timely manner.

- Patients should be given helpline details to arrange contact for advice regarding delayed deliveries.

- Maintaining a functional infusion service throughout the pandemic should be a priority.

\section{THERAPY SPECIFIC CONSIDERATIONS}

Given the paucity of data regarding the effects of IBD medications on the course of COVID-19, contributing confirmed cases to the international registry (SECURE-IBD, https://covidibd.org) is encouraged.

- Corticosteroids

- Should be avoided if possible but will still be necessary for some who should then observe 'shielding' while prednisolone dose is $\geq 20 \mathrm{mg}$ daily.

- High dose steroids are an established risk factor for respiratory tract infection and opportunistic infection in IBD and septicaemia. ${ }^{19} 20$

- Rapid tapering (10 mg/week) should be considered where possible. This must be balanced against the risks of extending steroid exposure overall by decreasing dose too quickly.

- Should not be stopped suddenly without advice.

- Consider using budesonide MMX (9 mg/day 8 weeks) or beclometasone ( $5 \mathrm{mg}$ /day 4 weeks) for patients with flaring UC (important to assess after 2 weeks).

- Consider using exclusive enteral nutrition for patients with flaring CD.

- Consider budesonide (Entocort, Budenofalk, $9 \mathrm{mg} / \mathrm{day}$ 8 weeks) for active small bowel and ileo-caecal CD.

- Immunomodulators (azathioprine, mercaptopurine, tioguanine, methotrexate, tacrolimus, mycophenolate mofetil)

- No current evidence of increased risk of COVID-19 infection.

- Initiation of monotherapy may not be appropriate.

- Combination therapy with biologics should be made on careful discussion of risk and benefit on a case by case basis.

- Older patients (>60 years) or those with significant comorbidity who are in sustained remission on thiopurines may wish to consider stopping after appropriate discussion with their IBD team.

Anti-tumour necrosis factor therapy (adalimumab, infliximab, golimumab, certolizumab)

- No current evidence of increased risk of COVID-19 infection.

- Consider initiation with monotherapy (therefore consider adalimumab to promote home care and lower risk of immunogenicity relative to infliximab).

- Use early therapeutic drug monitoring where possible, highlighting those appropriate for later combination immunosuppression where necessary.

- Enforced intravenous to subcutaneous switching is not recommended.

- Anti-interleukin-12/23p40 therapy (ustekinumab)

- No current evidence of increased risk of COVID-19 infection.

- One advantage of ustekinumab is a one off intravenous induction dose followed by subcutaneous maintenance dosing (minimal impact on infusion suite).

Anti- $\alpha 4 \beta 7$ integrin therapy (vedolizumab) 
- No current evidence of increased risk of COVID-19 infection.

- Unlikely to increase the risk of COVID-19 complications, although caution should be exercised in applying existing trial data to COVID-19.

- Janus kinase inhibitors (tofacitinib)

- No current evidence of increased risk of COVID-19 infection.

-5-Aminosalicylic acid derivatives (mesalazine)

- No current evidence of increased risk of COVID-19 infection.

- In UC patients with uncontrolled symptoms, oral 5 -aminosalicylic acid dose should be optimised with or without the addition of topical (rectal) 5-aminosalicylic acid.

\section{SERVICE CONSIDERATIONS}

Remote monitoring of disease activity can be achieved through virtual clinics using blood tests taken at sites remote to the hospital (eg, satellite facilities or via a general practitioner), with standard laboratory or point of care FC monitoring where available.

The infusion service is a priority area. Consider moving off site to a 'clean' area if possible or facility with alternative access, avoiding the need to pass through the main hospital. Visitors should no longer be permitted. Patients should not attend for infusion if they are symptomatic for COVID-19 and where possible should be screened on arrival for symptoms and fever. Two metre spacing should be employed between patients, and there should be a dedicated separate waiting area if possible. A strict hand washing policy on arrival should be enforced. Infusion chairs should be appropriately cleaned between patients. Parenteral electrolyte and iron replacement services should be reserved for urgent cases only. If capacity is reduced due to staff shortages, daily/weekly triage of infusions should take place.

\section{Endoscopy}

The BSG has provided separate guidance on endoscopy and COVID-19 (https://www.bsg.org.uk/covid-19-advice/). IBD surveillance procedures should be deferred. IBD disease assessment scopes will need to be carefully assessed for priority. Alternative methods of disease assessment, including the use of biomarkers, radiology and capsule endoscopy should be considered.

\section{Imaging}

The capacity for outpatient imaging may be reduced. However, this should be discussed within individual hospitals. Access to different imaging modalities may vary during the pandemic and this may influence the choice of investigation for patients with IBD.

\section{Surgery}

Routine elective operations have been deferred in most centres. Where possible, urgent management of perianal sepsis should be undertaken as a day case procedure. Complex IBD surgery should be deferred where possible and its timing should be reviewed regularly at multidisciplinary meetings. Emergency procedures (e.g. subtotal colectomy in acute severe UC, intestinal resection to control penetrating disease in $\mathrm{CD}$ ) will continue as part of routine care. As with active disease, the choice of postoperative therapy to prevent recurrence will need to be considered in the context of the COVID-19 pandemic. If surgery is required for subacute obstructive symptoms, it may be possible to avoid or delay surgery by using partial or exclusive enteral nutrition regimens. $^{21}$

\section{Clinical trials}

The National Institute for Health Research (NIHR) and Chief Scientist Office (CSO) have produced guidance on the management of clinical trials which will be updated regularly (NIHR https://www.nihr.ac.uk/news/dhsc-issues-guidance-on-theimpact-on-covid-19-on-research-funded-or-supported-by-nihr/ 24469; CSO http://www.nhsresearchscotland.co.uk/news/covid19---guidance-for-sponsors-sites-and-researchers). Many trials will have already been paused by their sponsors.

Where this has not happened, participant screening, recruitment and continuation (for participants already recruited) should be reviewed at the local level for appropriateness in the current clinical situation. The benefits of avoiding surgery and/or corticosteroids by receiving trial medication that may not be otherwise available must be balanced against the risk of face to face visits and the unknown effects of the investigational medicinal product on the course of COVID-19. Where possible, trial visits should occur virtually, and investigations that require hospital attendance should be postponed unless clinically important. Protocol amendments should be made to the relevant regulatory bodies, and advice should be sought from research and development directors promptly to protect participants, as formal approval may be significantly delayed. Blinded trials pose a particular concern; principal investigators should be prepared to unblind participants where the information will influence the participant's treatment or when assessment and management of coronavirus is being considered. In addition, patients who may be on a placebo medication that does not require self-isolation or social distancing should have this highlighted to them in case they wish to withdraw from a study. Sponsors should consider minimising the burden of administrative tasks while healthcare teams are stretched; many members of the research team are already being redeployed into direct clinical care.

\section{ADVICE FOR NHS STAFF WITH IBD}

Frontline staff with IBD should follow the same precautions as other IBD patients. However, given the high risk of exposure of frontline staff to SARS-CoV-2, it would be advisable that hospital teams consider utilising team members with IBD in roles where exposure is limited (i.e. telephone clinics as opposed to endoscopy lists and ward work), especially if that individual is at 'moderate' risk or has other comorbidity, in which case they should be supported in working from home if possible. If it is essential for them to work in a hospital environment, they should ensure they avoid close contact with other staff members and can maintain social distancing.

\section{CONCLUSION}

The COVID-19 pandemic has posed unprecedented challenges to healthcare providers across the globe. The IBD community must continue to demonstrate adaptability in this rapidly moving field. Collaborative working is vital to ensure we gather as much knowledge as possible collectively, sharing ideas to provide the best outcomes for our patients as new evidence emerges.

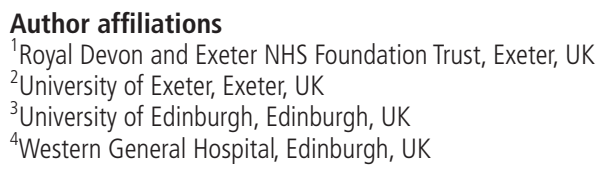


${ }^{5}$ Newcastle University, Newcastle upon Tyne, UK

${ }^{6}$ Newcastle upon Tyne Hospitals NHS Foundation Trust, Newcastle upon Tyne, UK

${ }^{7}$ Chelsea and Westminster Hospital NHS Foundation Trust, London, UK

${ }^{8}$ Southampton Children's Hospital, University Hospital Southampton NHS Foundation Trust, Southampton, UK

${ }^{9}$ University College London Hospitals NHS Foundation Trust, London, UK

${ }^{10}$ Sheffield Teaching Hospitals NHS Foundation Trust, Sheffield, UK

${ }^{11}$ Queen Elizabeth Hospital Birmingham NHS Foundation Trust, Birmingham, UK

${ }^{12}$ University of Birmingham, Birmingham, UK

${ }^{13}$ King's College London, London, UK

${ }^{14}$ The Royal Free Hospital, London, UK

${ }^{15}$ Torbay and South Devon NHS Foundation Trust, Torquay, UK

${ }^{16}$ University Hospitals Bristol NHS Foundation Trust, Bristol, UK

${ }^{17}$ Glasgow Royal Infirmary, Glasgow, UK

${ }^{18}$ University of Glasgow, Glasgow, UK

${ }^{19}$ Royal Hospital for Children, Glasgow, UK

${ }^{20}$ St Mark's Hospital, London, UK

${ }^{21}$ Imperial College London, London, UK

${ }^{22}$ University Hospital of Wales, Cardiff, UK

${ }^{23}$ King's College Hospital NHS Foundation Trust, London, UK

${ }^{24}$ The Pennine Acute Hospitals NHS Trust, Manchester, UK

${ }^{25}$ University of Manchester, Manchester, UK

${ }^{26} \mathrm{Barts}$ and the London School of Medicine and Dentistry, London, UK

${ }^{27}$ The Royal London Hospital, Barts Health NHS Trust, London, UK

${ }^{28}$ Cambridge University Hospitals NHS Foundation Trust, Cambridge, UK

${ }^{29}$ St George's University Hospitals NHS Foundation Trust, London, UK

${ }^{30}$ St George's, University of London, London, UK

${ }^{31}$ Imperial College Healthcare NHS Trust, London, UK

${ }^{32}$ Liverpool University Hospitals NHS Foundation Trusts, Liverpool, UK

${ }^{33}$ University of Liverpool, Liverpool, UK

${ }^{34}$ Hull University Teaching Hospitals NHS Trust, Hull, UK

${ }^{35}$ Leeds Teaching Hospitals NHS Trust, Leeds, UK

${ }^{36}$ Salford Royal NHS Foundation Trust, Salford, UK

${ }^{37}$ Crohn's and Colitis UK, St Albans, UK

${ }^{38}$ Guy's and St Thomas' NHS Foundation Trust, London, UK

Twitter Nicholas A Kennedy @DrNickKennedy, Gareth-Rhys Jones@gastro_GRJ, Christopher A Lamb @DrChrisLamb, Richard Appleby @rnappleby, R Mark Beattie @RMBeattie50, Alenka J Brooks@alenkabrooks, Robin J Dart @rjcdart, Cathryn Edwards@CathrynmEdwards, Daniel R Gaya @carmunnock, Richard Hansen @ paedsrh, A Barney Hawthorne @ABHawthorne, Bu'Hussain Hayee @IBDdoc, Jimmy K Limdi @jklimdi, Nick Powell @NickPowellLab, Chris S Probert @ChrisProbert62, Tim Raine @IBD_MB, Shaji Sebastian @ibdseb, Philip J Smith @DrPhilipJSmith, Catherine Stansfield @ibdportal, Lisa Younge @LisaYounge2 and Charlie W Lees @ charlie_lees

Acknowledgements This guidance has been developed by the British Society of Gastroenterology COVID-19 IBD Working Group and we are grateful for the input from contributors within the group. The British Society of Gastroenterology COVID-19 IBD Working Group is thankful for the support of Crohn's and Colitis UK in developing a patient friendly version of this guidance and to the UK IBD Registry for supporting development of a patient self-identification tool implementing the guidance.

Contributors CWL, NAK, G-RJ and CAL led the writing group. All authors contributed to either or both discussion regarding guidance set out in this manuscript and editing of the final document.

Funding The authors have not declared a specific grant for this research from any funding agency in the public, commercial or not-for-profit sectors.

Competing interests For details of conflicts of interest see online supplementary table 1.

Patient and public involvement Real time, valuable feedback from patients engaging with the IBD Registry and Crohn's and Colitis UK tools, as well as previous versions of this guidance on the British Society of Gastroenterology website, has helped clarify ambiguities in the original risk stratification grid. This has provided a powerful and unique mechanism for rapid patient-clinician co-development of this clinical guidance.

Patient consent for publication Not required.

Provenance and peer review Not commissioned; internally peer reviewed.

Data availability statement All data relevant to the study are included in the article.

Open access This is an open access article distributed in accordance with the Creative Commons Attribution Non Commercial (CC BY-NC 4.0) license, which permits others to distribute, remix, adapt, build upon this work non-commercially, and license their derivative works on different terms, provided the original work is properly cited, appropriate credit is given, any changes made indicated, and the use is non-commercial. See: http://creativecommons.org/licenses/by-nc/4.0/.

\section{ORCID iDs}

Nicholas A Kennedy http://orcid.org/0000-0003-4368-1961

Gareth-Rhys Jones http://orcid.org/0000-0001-7355-2357

Christopher A Lamb http://orcid.org/0000-0002-7271-4956

Richard Appleby http://orcid.org/0000-0001-5887-8922

Ian Arnott http://orcid.org/0000-0003-3352-9253

R Mark Beattie http://orcid.org/0000-0003-4721-0577

Stuart Bloom http://orcid.org/0000-0002-6361-4662

Alenka J Brooks http://orcid.org/0000-0001-7162-7845

Rachel Cooney http://orcid.org/0000-0003-3710-157X

Robin J Dart http://orcid.org/0000-0003-3470-8210

Cathryn Edwards http://orcid.org/0000-0002-5550-9184

Aileen Fraser http://orcid.org/0000-0001-6462-5091

Daniel R Gaya http://orcid.org/0000-0003-1942-7568

Subrata Ghosh http://orcid.org/0000-0002-1713-7797

Kay Greveson http://orcid.org/0000-0003-4713-7306

Richard Hansen http://orcid.org/0000-0002-3944-6646

Ailsa Hart http://orcid.org/0000-0002-7141-6076

A Barney Hawthorne http://orcid.org/0000-0002-8768-4550

Bu'Hussain Hayee http://orcid.org/0000-0003-1670-8815

Jimmy K Limdi http://orcid.org/0000-0002-1039-6251

Charles D Murray http://orcid.org/0000-0001-6736-1546

Gareth C Parkes http://orcid.org/0000-0002-5285-7714

Miles Parkes http://orcid.org/0000-0002-6467-0631

Richard C Pollok http://orcid.org/0000-0001-6452-6763

Nick Powell http://orcid.org/0000-0003-3231-6950

Chris S Probert http://orcid.org/0000-0003-0477-6714

Tim Raine http://orcid.org/0000-0002-5855-9873

Shaji Sebastian http://orcid.org/0000-0002-3670-6545

Christian Selinger http://orcid.org/0000-0003-2022-5859

Philip J Smith http://orcid.org/0000-0003-1568-3978

Catherine Stansfield http://orcid.org/0000-0002-7775-2337

Lisa Younge http://orcid.org/0000-0002-3436-9696

James 0 Lindsay http://orcid.org/0000-0003-3353-9590

Peter M Irving http://orcid.org/0000-0003-0972-8148

Charlie W Lees http://orcid.org/0000-0002-0732-8215

\section{REFERENCES}

1 Jones G-R, Lyons M, Plevris N, et al. IBD prevalence in Lothian, Scotland, derived by capture-recapture methodology. Gut 2019;68:1953-60.

2 Jones GR, Lyons M, Plevris N, et al. A capture-recapture study of all-age IBD point prevalence. Gut 2019;68:A63-4.

3 Lichtenstein GR, Feagan BG, Cohen RD, et al. Serious infection and mortality in patients with Crohn's disease: more than 5 years of follow-up in the TREATTM registry. Am J Gastroenterol 2012;107:1409-22.

4 Guan W-jie, Ni Z-yi, Hu Y, et al. Clinical characteristics of coronavirus disease 2019 in China. N Engl J Med 2020

5 Zhou F, Yu T, Du R, et al. Clinical course and risk factors for mortality of adult inpatients with COVID-19 in Wuhan, China: a retrospective cohort study. Lancet 2020;395:1054-62.

6 Integrated surveillance of COVID-19 in Italy. The COVID-19 Task force of the Department of Infectious Diseases and the IT Service Istituto Superiore di Sanit, 2020. Available: https://www.epicentro.iss.it/coronavirus/bollettino/Infografica_19marzo\% 20ENG.pdf [Accessed 24th Mar 2020].

7 Yang J, Zheng Y, Gou X, et al. Prevalence of comorbidities in the novel Wuhan coronavirus (COVID-19) infection: a systematic review and meta-analysis. Int J Infect Dis 2020. doi:10.1016/j.ijid.2020.03.017

8 Vardavas Cl, Nikitara K. COVID-19 and smoking: a systematic review of the evidence. Tob Induc Dis 2020;18:20.

9 Wenham C, Smith J, Morgan R, et al. COVID-19: the gendered impacts of the outbreak. Lancet 2020;395:846-8.

10 Little P, Moore M, Kelly J, et al. Ibuprofen, paracetamol, and steam for patients with respiratory tract infections in primary care: pragmatic randomised factorial trial. BMJ 2013;347:f6041.

11 Little P, Stuart B, Andreou P, et al. Primary care randomised controlled trial of a tailored interactive website for the self-management of respiratory infections (Internet doctor). BMJ Open 2016;6:e009769.

12 Lamb CA, Kennedy NA, Raine T, et al. British Society of Gastroenterology consensus guidelines on the management of inflammatory bowel disease in adults. Gut 2019;68:s1-106

13 SECURE-IBD Registry. SECURE-IBD registry: surveillance epidemiology of coronavirus (COVID-19) under research exclusion, 2020. Available: https://covidibd.org/currentdata/ [Accessed 27th Mar 2020]. 
14 International Organization for the Study of Inflammatory Bowel Disease. IOIBD Update on COVID19 for Patients with Crohn's Disease and Ulcerative Colitis, 2020. Available: https://www.ioibd.org/ioibd-update-on-covid19-for-patients-with-crohnsdisease-and-ulcerative-colitis/ [Accessed 27th Mar 2020].

15 European Crohn's and Colitis Organisation. 1St interview COVID-19 ECCO Taskforce, 2020. Available: https://ecco-ibd.eu/images/6_Publication/6_8_Surveys/ 1st_interview_COVID-19\%20ECCOTaskforce_published.pdf [Accessed 27th Mar 2020].

16 Mao R, Liang J, Shen J, et al. Implications of COVID-19 for patients with pre-existing digestive diseases. Lancet Gastroenterol Hepatol 2020:426-8.

17 An P, Ji M, Ren H, et al. Protection of 318 inflammatory bowel disease patients from the outbreak and rapid spread of COVID-19 infection in Wuhan, China. Available: https://ssrn.com/abstract=3543590 [Accessed 27th Feb 2020].
18 Wisniewski A, Kirchgesner J, Seksik P, et al. Increased incidence of systemic serious viral infections in patients with inflammatory bowel disease associates with active disease and use of thiopurines. United Eur Gastroenterol J 2019:22:205064061988976.

19 Naganuma M, Kunisaki R, Yoshimura N, et al. A prospective analysis of the incidence of and risk factors for opportunistic infections in patients with inflammatory bowel disease. J Gastroenterol 2013;48:595-600.

20 Fardet L, Petersen I, Nazareth I. Common infections in patients prescribed systemic glucocorticoids in primary care: a population-based cohort study. PLoS Med 2016;13:e1002024.

21 Heerasing N, Thompson B, Hendy P, et al. Exclusive enteral nutrition provides an effective bridge to safer interval elective surgery for adults with Crohn's disease. Aliment Pharmacol Ther 2017:45:660-9. 